\title{
Hands down: Reflecting on the 50th anniversary of the description of Trisomy 21
}

\author{
Vincent M. Riccardi, $M D$
}

In July 1968, on the first day of my genetics fellowship, I presented myself to Leonard Atkins, MD, director of the Cytogenetics Laboratory at the Massachusetts General Hospital. He looked at me and simply asked, "Can you count?" In response to my affirmative nod, he pointed to the Zeiss photomicroscope on the laboratory table between us and said, "Start counting." No preface or further explanation was necessary. By then, even the dullest recent medical school graduate knew that a variety of disorders might be identified or documented by showing an increase or decease in the number of chromosomes in a cultured cell: 45 was too few and 47 or more was too many. By then, it had already been 9 years since Jérôme Lejeune established that Trisomy 21 accounts for Down syndrome.

A little over a year later, in San Francisco, October 3, 1969, I was part of a relatively small but admiring audience as Dr. Lejeune gave the William Allan Memorial Award address to the annual meeting of the American Society of Human Genetics. Clearly, his documentation that changes in human chromosome numbers could account for a variety of human disorders had changed medicine and genetics forever. And Trisomy 21 was the unfurled banner leading the way. In any event, I was hooked then and there, determined thereby to be in the vanguard of clinical cytogenetics.

In August of 1978, I visited Dr. Lejeune in his laboratory in Paris, where I was fascinated by his innumerable poster-board drawings of interrelated biochemical systems as he tried to conjure a systematic approach to overcoming and abrogating the clinical consequences of aneuploidy, particularly Trisomy 21. Since then, of course, the genetic emphasis has been on the DNA that comprises Chromosome 21, thereby seeking another type of handle on the interactomes that ultimately impinge on Trisomy 21 pathogenesis.

But, there is another side to Trisomy 21, to Down syndrome, that is not about genes and molecules and, in any event, has been seriously overlooked by geneticists. In the 50 years since Lejeune's publication, we have made little progress in terms of minimizing the disorder's compromising clinical and social impact. At least in part this is due to displacing our most imaginative thinking to the genome, the proteome and the interactome. So, I want to suggest something different. The occasion of this cytogenetic celebration might also be an opportunity to consider new approaches to physical therapy and technology-based enhancements of neuromuscular development at critical stages in the lives of youngsters with Down syndrome.

Vincent M. Riccardi, MD, 5415 Briggs Avenue, La Crescenta, CA 91214. E-mail: riccardi@medconsumer.com.

The author declares no conflict of interest.

Submitted for publication June 5, 2009.

Accepted for publication June 14, 2009.

Published online ahead of print August 17, 2009.

DOI: $10.1097 /$ GIM.0b013e3181b2e36f
I have long had an interest in the hand as an instrument of language and its more general role in intellectual development. Children learn by using their hands - as opposed to one following on the other, that is, learning and then translating what has been learned to the hand. In this context, in May 2003, I immersed myself in one of the books by the renowned neurologist, Frank R. Wilson, The Hand: How its use shapes the brain, language and human culture. ${ }^{1}$ In particular, on Pages 103 and 104 of that book, the purveyor of infant and toddler neuromuscular development finds several tantalizing sentences and phrases that are likely to be very relevant to the youngster with Down syndrome: “. . . to prepare the young child for walking and maneuvering among objects that move independently in the environment ... [t] he first essential milestone in this development is the creation of a stable platform for the visual system (the head supported on the neck) so that the eyes can reliably guide movement of the upper limbs ... the impulse to reach and then to grasp (catch), is one of the earliest maturational imperatives in the human nervous system . . . [o]ne of the most important physiological consequences of these accumulated body lessons in physics is the establishment of an internal temporal reference system-a biologic clock ... the accuracy of a toss depends on when you let go . . . you will never be able to throw accurately enough to hit a target unless your own internal clock, which controls the timing of muscle activity, is perfectly calibrated ... that clock is not set or calibrated until the head is under control. And when that time comes, the setting and calibration is organized through active movement, including the catching games a child plays ... The development of any high-level skill requires intelligent rehearsal: repetition according to a well-designed plan." These considerations resonate especially strongly in the context of the notation on Page 98 that ". . . when the head is supported in an upright position, babies between 5 and 8 weeks old will reach with the accuracy of babies 20 weeks old." There is a limited window of time during which a child can learn and enhance limb coordination based on good head control. If that window is obscured by poor head control and generalized muscular hypotonia, many skill potentials are severely compromised, if not totally lost.

In short, the child with Down syndrome and its attendant diffuse muscular hypotonia and often profound head lag-i.e., lack of minimal head control, lack of a "stable platform"-will not be able to develop the substantial hand-eye coordination that is requisite for later acquisition of more mature manual dexterity and language skills. The child cannot graduate to normally sophisticated muscular control involving the hand if he or she cannot hold the head straight on the neck. These considerations suggest that stabilizing the head of a child with Down syndrome artificially to afford a "stable platform" during a critical time period in the first 4 months of life may make possible better neuromuscular and language performance than we have seen otherwise among children compromised by Trisomy 21 .

My intention here is not to convince the reader that we should immediately embark on this type of neurodevelopmental physical therapy for children with Down syndrome. Rather, if my discourse is at all cogent, the point is to draw attention to the 
fact that there is a dearth of imaginative and innovative thinking by geneticists about Down syndrome beyond the genome, the proteome, and the interactome. Perhaps, in this year of the 50th anniversary of Lejeune's publication cementing Trisomy 21 into our genetic thinking, we may be able to focus more thoughtfully on the patients themselves and not their "-omes."
Actually, however, one other-ôme does come to mind: I think Jérôme Jean Louis Marie Lejeune would be pleased.

\section{REFERENCE}

1. Wilson FR. The hand: how its use shapes the brain, language and human culture. New York: Pantheon Books, 1998:1-397. 